\title{
Neutrophil Gelatinase-Associated Lipocalin, Fibroblast Growth Factor 23, and Soluble Klotho in Long-Term Kidney Donors
}

\author{
Inga Strand Thorsen $^{a} \quad$ Inger Hjørdis Bleskestad $^{a} \quad$ Grete Jonsson $^{b}$ \\ Øyvind Skadberg ${ }^{b}$ Lasse Gunnar Gøransson ${ }^{\text {a, c }}$ \\ Departments of anternal Medicine and ${ }^{b}$ Medical Biochemistry, Stavanger University \\ Hospital, Stavanger, and 'Department of Clinical Medicine (K1), University of Bergen, \\ Bergen, Norway
}

\section{Key Words}

Kidney donors · Biomarkers · Neutrophil gelatinase-associated lipocalin · Klotho · Fibroblast growth factor $23 \cdot$ Vitamin D $\cdot$ Kidney transplantation

\begin{abstract}
Background: The best treatment for end-stage renal disease (ESRD) is kidney transplantation. Twenty-seven percent of transplantations in Norway are from living donors. Recent studies have shown an increased risk of ESRD and increased mortality in donors. The aim of this study was to determine if the levels of the new biomarkers neutrophil gelatinase-associated lipocalin (NGAL), soluble Klotho (sKlotho), and fibroblast growth factor 23 (FGF23) are changed in kidney donors with normal kidney function defined as an estimated glomerular filtration rate (eGFR) $>60 \mathrm{ml} / \mathrm{min} / 1.73 \mathrm{~m}^{2}$ compared to patients with chronic kidney disease (CKD) stages 3-5 and healthy controls. Methods: This is a cross-sectional, observational, single-center study including 35 kidney donors with an eGFR $\geq 60 \mathrm{ml} / \mathrm{min} / 1.73 \mathrm{~m}^{2} 5$ years after donation, 22 patients with CKD stage 3 (eGFR $30-59 \mathrm{ml} / \mathrm{min} / 1.73 \mathrm{~m}^{2}$ ), 18 patients with CKD stage 4 (eGFR $15-29 \mathrm{ml} / \mathrm{min} / 1.73 \mathrm{~m}^{2}$ ), 20 patients with CKD stage 5 (eGFR $<15 \mathrm{ml} / \mathrm{min} / 1.73 \mathrm{~m}^{2}$ ), and $35 \mathrm{con}$ trols comparing levels of biomarkers in long-term kidney donors with those in CKD patients and healthy controls. Results: The level of log NGAL was significantly higher in donors than in healthy controls ( $2.02 \pm 0.10 \mathrm{vs.} 1.89 \pm 0.10 \mathrm{ng} / \mathrm{ml} ; \mathrm{p}<0.001)$, and the level increased with declining kidney function. The log FGF23 level was nonsignificantly higher in donors than in controls, but it significantly increased with declining kidney function. The log sKlotho levels were significantly lower in patients with CKD stages 4 and 5 than in controls, but no difference was revealed between controls and donors. Conclusion: Kidney donors have significantly higher levels of NGAL than healthy controls after a median of 15 years (range 5-38). NGAL could be a valuable diagnostic marker in the future. FGF23 and sKlotho were not significantly different between donors and controls.


Thorsen et al.: Neutrophil Gelatinase-Associated Lipocalin, Fibroblast Growth

Factor 23, and Soluble Klotho in Long-Term Kidney Donors

\section{Introduction}

In Norway the prevalence of chronic kidney disease (CKD) is $10.2 \%$ according to the second Health Survey of Nord-Trøndelag [1]. The same prevalence is reported from the USA [2]. CKD is characterized by progressive destruction of the renal parenchyma and loss of functional nephrons [3]. Only a group of patients with CKD stages 3-4 develop end-stage renal disease (ESRD) with the need for dialysis or transplantation [4].

The best treatment for ESRD is kidney transplantation. In 2013, 246 kidney transplantations were performed in Norway, of which 68 (27.6\%) were from a living donor [5]. The short- and long-term effects of unilateral nephrectomy on living donors have been an important issue for more than 60 years. A living donor must undergo a medically unnecessary procedure, and safety concerns have always been the focus of attention. The short-term risk is well established with a $0.03 \%$ risk of mortality and $<1 \%$ risk of major morbidity [6]. The loss of renal mass from unilateral nephrectomy in living kidney donors is associated with compensatory changes in the remaining kidney [7], and a rapid compensatory increase in glomerular filtration rate (GFR) in the remaining kidney is well documented [8].

Earlier studies claimed that living kidney donors neither have an increase in all-cause mortality nor an increased risk of ESRD compared to the general population. However, donors are selected from a group of very healthy individuals thoroughly screened for conditions such as hypertension and kidney and coronary diseases, and they do not reflect the general population. New studies comparing donors with equally healthy controls indicate an increased risk of metabolic derangements particularly involving calcium homeostasis, kidney failure, and mortality $[9,10]$.

The function of neutrophil gelatinase-associated lipocalin (NGAL) is largely unknown, but NGAL is associated with cellular stress, acute kidney injury, and CKD $[11,12]$. Fibroblast growth factor 23 (FGF23) has an important role in calcium-phosphate metabolism, and FGF23 levels rise quickly as kidney function declines [13]. Soluble Klotho (sKlotho) is linked to aging and CKD progression. These biomarkers have a known association with CKD progression, but they are not adequately explored in long-term kidney donors [14]. The aim of this study was to determine if the levels of the new biomarkers NGAL, sKlotho, and FGF23 are changed in kidney donors with normal kidney function defined as an estimated GFR (eGFR) $>60 \mathrm{ml} /$ min/1.73 $\mathrm{m}^{2}$ compared to healthy controls and patients with CKD.

\section{Subjects and Methods}

The study is a cross-sectional, observational, single-center trial. Donors and patients with CKD stages 3 and 4 were identified in a local database containing all patients visiting the outpatient clinic at the renal unit of Stavanger University Hospital. Patients were included in connection with planned appointments and after giving informed consent. Patients with CKD stage 5 were all recruited from the hemodialysis unit. Patients with severe comorbidity and a limited life expectancy, as well as previously parathyroidectomized patients, were excluded. We included donors with an eGFR $\geq 60 \mathrm{ml} / \mathrm{min} / 1.73 \mathrm{~m}^{2}$ to avoid confounding with regard to the levels of the new biomarkers from reduced eGFR, and only patients with a follow-up of $>5$ years after donor nephrectomy. The time since nephrectomy varied from 5 to 38 years (median 15). We included 35 kidney donors with an eGFR $\geq 60 \mathrm{ml} / \mathrm{min} / 1.73 \mathrm{~m}^{2}, 22$ patients with CKD stage 3 (eGFR 30-59 ml/min/1.73 m²), 18 patients with CKD stage 4 (eGFR 15-29 $\mathrm{ml} / \mathrm{min} / 1.73 \mathrm{~m}^{2}$ ), and 20 patients with CKD stage 5 (eGFR $<15 \mathrm{ml} / \mathrm{min} / 1.73 \mathrm{~m}^{2}$ ).

Thirty-five healthy controls were recruited from among colleagues and friends who regarded themselves as healthy. All patients and controls were older than 18 years. Written 
Thorsen et al.: Neutrophil Gelatinase-Associated Lipocalin, Fibroblast Growth

Factor 23, and Soluble Klotho in Long-Term Kidney Donors

informed consent was obtained from all patients, donors, and controls prior to their inclusion. The study adhered to the Declaration of Helsinki and was approved by the Regional Medical and Health Research Ethics Committee Western Norway.

Routine hematological and biochemical analyses, including hemoglobin, creatinine, calcium, phosphate, intact parathyroid hormone (iPTH), albumin, and electrolytes, were performed at the hospital's analytical laboratory. Urine samples were analyzed for albumin, creatinine, calcium, and phosphate in all participants except ESRD patients.

NGAL was analyzed in EDTA plasma, whereas 25(OH) vitamin D, sKlotho, and FGF23 were analyzed in serum. Serum and EDTA plasma were separated from blood cells within $1 \mathrm{~h}$ after collection by centrifugation for $15 \mathrm{~min}$ at $2,500 \mathrm{~g}$ at $4{ }^{\circ} \mathrm{C}$, and stored in aliquots at $-76^{\circ} \mathrm{C}$ until analysis.

The eGFR was estimated using the Chronic Kidney Disease Epidemiology Collaboration (CKD-EPI) equation [15]. Serum phosphate (reference range: females 0.85-1.44 mmol/l; males $13-49$ years $0.78-1.52 \mathrm{mmol} / \mathrm{l}, \geq 50$ years $0.69-1.31 \mathrm{mmol} / \mathrm{l})$, total serum calcium (reference range $2.15-2.55 \mathrm{mmol} / \mathrm{l}$ ), and albumin (reference range: 0-39 years 36-48 g/l, 40-69 years 36-45 g/l, $\geq 70$ years 34-45 g/l) were analyzed using Architect c16000TM (Abbott Diagnostics, Abbott Park, Ill., USA). Albumin-corrected serum calcium (reference range: females $<54$ years $2.17-2.52 \mathrm{mmol} / \mathrm{l}, \geq 55$ years $2.20-2.62 \mathrm{mmol} / \mathrm{l}$; males $2.17-2.56$ $\mathrm{mmol} / \mathrm{l})$ was calculated as follows: serum calcium $+0.02 \times(41.3-$ serum albumin $)$. iPTH (reference range: 1.6-8.5 pmol/l) was determined using an intact PTH assay from Abbott Diagnostics, analyzed on an Architect i2000SR (Abbott Diagnostics).

Serum iFGF23 and sKlotho were measured by commercially available ELISA kits from Kainos Laboratories Inc. (Tokyo, Japan) and IBL (Immuno-Biological Laboratories GmbH, Hamburg, Germany), respectively. Freshly thawed samples were measured in duplicate, and the reproducibility of the methods was monitored by analyzing 3-5 aliquots of a serum control with each assay. The intra- and interassay coefficients of variation for sKlotho were $<15 \%$, and for iFGF23 they were $<7$ and $<11 \%$, respectively. The level of iFGF23, measured with the Kainos ELISA kit, in 104 healthy adults from Japan was reported to be in the range of 8.2-54.3 ng/l [16], and a reference range of 10-50 $\mathrm{ng} / \mathrm{l}$ has been suggested based on these results [17]. sKlotho, measured by the IBL ELISA kit in serum from 142 healthy subjects, was reported to range from 239 to $1,266 \mathrm{pg} / \mathrm{ml}$, with a mean of $562 \pm 146 \mathrm{pg} / \mathrm{ml}$, in the original publication on the method [18]. Reference ranges for males of $252-652 \mathrm{pg} / \mathrm{ml}$ and for females of $177-804 \mathrm{pg} / \mathrm{ml}$ in a healthy Danish population were recently published using the same ELISA kit [19]. Serum 25(OH) vitamin D was quantified by liquid-liquid extraction, derivatization with 4-phenyl-1,2,4-triazoline-3,5-dione reagent (PTAD; Sigma-Aldrich, St. Louis, Mo., USA), and analysis by liquid chromatography coupled with tandem mass spectrometry detection [20]. Levels of serum $25(\mathrm{OH})$ vitamin D are deficient below $50 \mathrm{nmol} / \mathrm{l}$, insufficient between 50 and $75 \mathrm{nmol} / \mathrm{l}$, and sufficient above $75 \mathrm{nmol} / \mathrm{l}$ [21]. The NGAL concentration in EDTA plasma was measured with a commercially available ELISA kit, with microwells precoated with a monoclonal antibody raised against human NGAL (KIT 036; Bio-Porto Diagnostics, Gentofte, Denmark). The analyses were performed in accordance with the manufacturer's protocol. Freshly thawed samples were measured in duplicate, and the reproducibility of the method was monitored by analyzing 4 duplicates of a plasma control with each assay. The intra- and interassay coefficients of variation were $<10$ and $<8 \%$, respectively [22].

The urine samples were analyzed for concentrations of creatinine (reference range: 4.5-20.0 $\mathrm{mmol} / \mathrm{l}$ ), albumin, calcium (reference range: 2.0-9.0 mmol/l), and phosphate. The fractional excretion of phosphate $\left(\mathrm{FePO}_{4}\right)$ was calculated as follows: (urine phosphate $\times$ serum creatinine) $\times 100 /$ (serum phosphate $\times$ urine creatinine). The reference range for $\mathrm{FePO}_{4}$ in healthy subjects is reported to be $0-20 \%$ [23]. The fractional excretion of calcium $\left(\mathrm{FeCa}_{3}\right)$ was calculated as follows: (urine calcium $\times$ serum creatinine) $\times 100 /($ serum calcium $\times$ urine creatinine). 
Thorsen et al.: Neutrophil Gelatinase-Associated Lipocalin, Fibroblast Growth

Factor 23, and Soluble Klotho in Long-Term Kidney Donors

Table 1. Baseline characteristics

\begin{tabular}{|c|c|c|c|c|c|c|}
\hline Group & $\begin{array}{l}\text { Control } \\
(n=35)\end{array}$ & $\begin{array}{l}\text { Donor } \\
(n=35)\end{array}$ & $\begin{array}{l}\text { CKD stage } 3 \\
(n=22)\end{array}$ & $\begin{array}{l}\text { CKD stage } 4 \\
(n=18)\end{array}$ & $\begin{array}{l}\text { CKD stage } 5 \text { (HD) } \\
(\mathrm{n}=20)\end{array}$ & $\begin{array}{l}\mathrm{p} \\
\text { value }\end{array}$ \\
\hline Age, years & $43.6 \pm 13.1$ & $56.5 \pm 9.4$ & $62.7 \pm 16.7$ & $61.7 \pm 17.1$ & $70.9 \pm 16.6$ & $<0.001$ \\
\hline Sex - male/female, $n$ & $16 / 19$ & $21 / 14$ & $15 / 7$ & $11 / 7$ & $12 / 8$ & 0.102 \\
\hline $\mathrm{NGAL}, \mathrm{ng} / \mathrm{ml}$ & $97.6 \pm 18.3$ & $110.6 \pm 31.7$ & $209.2 \pm 67.5$ & $459.5 \pm 111.3$ & $1,012.6 \pm 374.1$ & $<0.001$ \\
\hline $\log$ NGAL, ng/ml & $1.89 \pm 0.10$ & $2.02 \pm 0.10$ & $2.3 \pm 0.15$ & $2.65 \pm 0.12$ & $2.98 \pm 0.17$ & $<0.001$ \\
\hline FGF23, pg/ml & $51.8(25.9-90)$ & $62.6(6.6-112)$ & $97.5(44-308)$ & $337.0(139-11,000)$ & $806.0(121-16,100)$ & $<0.001$ \\
\hline sKlotho, pg/ml & $725.4(458-1,222)$ & $669.3(409-1,161)$ & $597.8(449-979)$ & $460.8(288-790)$ & $377.6(223-784)$ & $<0.001$ \\
\hline $25(\mathrm{OH})$ vitamin $\mathrm{D}, \mathrm{nmol} / \mathrm{l}$ & $58.67 \pm 25.2$ & $76.4 \pm 17.0$ & $44.01 \pm 19.4$ & $53.55 \pm 22.5$ & $59.65 \pm 29.5$ & $<0.001$ \\
\hline $\mathrm{eGFR}, \mathrm{ml} / \mathrm{min} / 1.73 \mathrm{~m}^{2}$ & $99.0 \pm 13.1$ & $75.8 \pm 12.3$ & $43.7 \pm 9.8$ & $19.1 \pm 5.8$ & $7.3 \pm 2.6$ & $<0.001$ \\
\hline Creatinine, $\mu \mathrm{mol} / \mathrm{l}$ & $73.1 \pm 12.6$ & $90.3 \pm 16.3$ & $141.0 \pm 28.1$ & $280.1 \pm 84.2$ & $621.2 \pm 203.6$ & $<0.001$ \\
\hline Albumin-corrected calcium, $\mu \mathrm{mol} / \mathrm{l}$ & $2.4 \pm 0.07$ & $2.41 \pm 0.06$ & $2.46 \pm 0.13$ & $2.45 \pm 0.13$ & $2.5 \pm 0.18$ & 0.006 \\
\hline iPTH, pmol/l & $5.82 \pm 2.47$ & $7.1 \pm 2.29$ & $13.63 \pm 13.19$ & $32.73 \pm 24.34$ & $47.43 \pm 46.86$ & $<0.001$ \\
\hline Phosphate, mmol/l & $1.12 \pm 0.17$ & $1.06 \pm 0.19$ & $1.11 \pm 0.16$ & $1.35 \pm 0.27$ & $1.46 \pm 0.49$ & $<0.001$ \\
\hline Urine phosphate, mmol/l & $16.4(2.4-49.9)$ & $25.8(2.6-50.7)$ & $17.2(4.1-31.8)$ & $13.7(6.5-27.8)$ & $\mathrm{nn}$ & 0.001 \\
\hline Urine calcium, mmol/l & $2.84 \pm 2.06$ & $1.96 \pm 1.09$ & $1.53 \pm 1.11$ & $0.77 \pm 0.12$ & nn & $<0.001$ \\
\hline Urine albumin/creatinine, $\mathrm{mg} / \mathrm{mmol}$ & $0.61(0.18-30.8)$ & $2.3(0.1-19.9)$ & $21.5(2.0-2,000.0)$ & $198(3.3-1,753.0)$ & nn & $<0.001$ \\
\hline $\mathrm{FePO}_{4}$ & $12.0(4.0-22.9)$ & $22.7(3.1-41.9)$ & $30.5(19.9-56.9)$ & $47.9(31.6-69.1)$ & nn & $<0.001$ \\
\hline $\mathrm{FeCa}_{3}$ & $0.84(0.20-2.5)$ & $0.78(0.16-1.73)$ & $0.79(0.35-3.03)$ & $1.13(0.43-3.15)$ & $\mathrm{nn}$ & 0.025 \\
\hline
\end{tabular}

Laboratory results are given as means \pm SD of normally distributed data, and as medians (ranges) of non-normally distributed data. $\mathrm{p}$ values display differences between groups, using one-way ANOVA for numeric values and the $\chi^{2}$ test for the categorical value 'sex'. Urine values in CKD stage 5 are marked as 'nn', because the included patients were on HD and had very limited urine production, which is why no urine samples were obtained. HD = Hemodialysis.

\section{Statistical Analysis}

All variables normally distributed are expressed as means \pm standard deviations. Other distributed data are expressed as medians and ranges. NGAL, sKlotho, and FGF23 were logarithmically transformed to obtain normal distributions.

The variables were compared by one-way ANOVA. The Mann-Whitney U test and KruskalWallis test gave similar results. We used a multiple regression model with the biomarkers NGAL, FGF23, and sKlotho as dependent variables to explore the possible effects of the independent variables age, sex, $25(\mathrm{OH})$ vitamin $\mathrm{D}$, phosphate, iPTH, albumin-corrected calcium, creatinine, and the other 2 biomarkers on the dependent variables. NGAL, FGF23, and sKlotho were used as dependent variables in 3 different models. We excluded nonsignificant variables using a backward selection model. We performed the analysis on the complete study population to ensure an adequate sample size.

The level of statistical significance was defined as $\mathrm{p}<0.05$. All statistical analyses were conducted using IBM SPSS Statistics version 22.0.

\section{Results}

The baseline characteristics are given in table 1 . The mean age of the controls was significantly lower than that of the other groups, and the mean age of the patients with CKD stage 5 was significantly higher.

The levels of log NGAL were significantly different between all groups, showing increasing levels with declining kidney function (fig. 1). Post hoc testing showed a significantly higher level of log NGAL in donors than in healthy controls $(\mathrm{p}<0.01)$. Post hoc testing also showed differences between controls and patients with CKD stages 3-5 and between each group of patients with CKD stages 3, 4, and 5. There was no association between NGAL levels and time since nephrectomy, NGAL levels and age, or NGAL levels and 1st-degree relationship between donors and recipients. In a multiple regression analysis using log NGAL as the dependent variable and age, sex, $25(\mathrm{OH})$ vitamin $\mathrm{D}$, phosphate, $\mathrm{iPTH}$, albumin-corrected calcium, log sKlotho, log FGF23, and creatinine as independent variables, only creatinine remained in the model using a backward selection model. 
Fig. 1. Boxplot showing the distribution of plasma log NGAL in the different groups. The levels of log NGAL are significantly different between the groups. CKD = Chronic kidney disease.

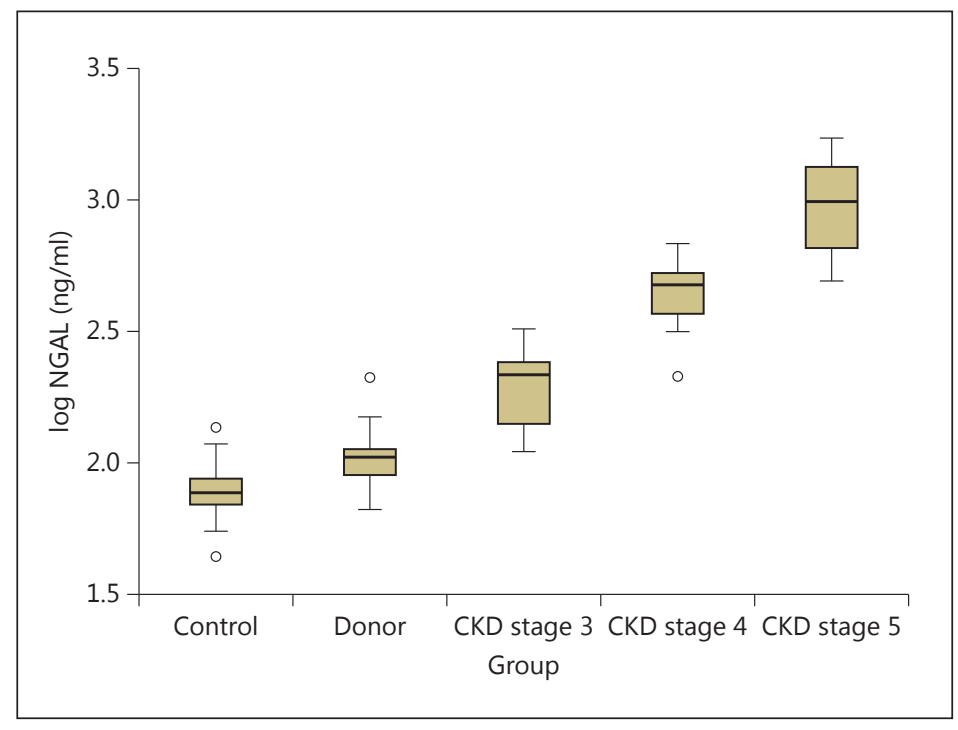

log FGF23 levels were nonsignificantly higher in donors than in controls - and, as expected, log FGF23 levels increased significantly with declining kidney function. In a multiple regression analysis using log FGF23 as the dependent variable and age, sex, 25(OH) vitamin D, creatinine, phosphate, albumin-corrected calcium, iPTH, log sKlotho, and log NGAL as independent variables, only serum phosphate, albumin-corrected calcium, and iPTH remained in the model using a backward selection model.

There was no difference in log sKlotho levels between controls and kidney donors. log sKlotho levels declined with declining kidney function, and the log sKlotho levels were significantly lower in patients with CKD stages 4 and 5 than in controls. There was no difference in log sKlotho levels between donors and controls. In a multiple regression analysis, there was no association between log sKlotho levels and age, sex, 25(OH) vitamin D, phosphate, iPTH, albumin-corrected calcium, log NGAL, or log FGF23. Creatinine was the only variable remaining in a backward selection model.

The kidney donors had an eGFR $\geq 60 \mathrm{ml} / \mathrm{min} / 1.73 \mathrm{~m}^{2}$, but the eGFR was significantly lower and creatinine significantly higher than in the control group. In comparison to healthy controls, living kidney donors had significantly higher levels of iPTH ( $p=0.03)$, significantly higher fractional urinary excretion of phosphate $(\mathrm{p}<0.001)$, nonsignificantly lower serum phosphate $(\mathrm{p}=0.23)$, and similar serum calcium levels. The donors also had significantly higher 25(OH) vitamin D levels than all the other groups. 25(OH) vitamin D levels were significantly lower in patients with CKD stage 3 , with $73 \%$ of the patients having serum levels $<50$ $\mathrm{nmol} / \mathrm{l}$.

\section{Discussion}

Long-term kidney donors with an eGFR $>60 \mathrm{ml} / \mathrm{min} / 1.73 \mathrm{~m}^{2}$ have significantly increased levels of NGAL compared to controls as well as to patients with CKD stages 3-5 after 5-38 years (median 15). Levels of NGAL and FGF23 have an inverse association with eGFR, and the level of sKlotho declines when the eGFR declines.

NGAL was originally isolated from the supernatant of activated neutrophilic granulocytes $[24,25]$. NGAL is also produced in other types of tissue, such as the kidneys. The function 
Thorsen et al.: Neutrophil Gelatinase-Associated Lipocalin, Fibroblast Growth

Factor 23, and Soluble Klotho in Long-Term Kidney Donors

of NGAL is largely unknown, but NGAL is increased in cells under 'stress' - for instance, during infections, inflammation, degeneration, or neoplastic transformation [11]. NGAL is associated with reduced kidney function in patients with CKD [12]. It is also associated with reduced kidney function in kidney transplant patients, and it is increased in stable transplant patients with subclinical tubulitis [26]. Studies of delayed kidney graft function have shown an association between delayed kidney graft function and urinary levels of NGAL and interleukin-18 on the first day after transplantation $[27,28]$. Interleukin-18 is a proinflammatory cytokine and a marker of oxidative stress [29]. The increased levels of NGAL in our kidney donors may reflect a state of increased cellular 'stress' which can induce cardiovascular disease (CVD) and kidney failure.

In a prospective observational cohort study on patients with CKD stage 3 or 4 , urinary NGAL was associated with an independent higher risk of death and initiation of renal replacement therapy [30]. In another study, plasma and urinary levels of NGAL were independent predictors of CKD progression even after adjusting for eGFR [31].

The hypothesis called the 'forest fire theory' claims that the increase in NGAL in CKD patients is the result of a sustained production of 'inflamed' but vital tubular cells, whereas reduced kidney function is a general loss of functional cells and nephrons. NGAL may therefore represent a real-time biomarker for ongoing kidney damage [32].

Immediately following a unilateral nephrectomy, renal blood flow increases by approximately $40 \%$. This is associated with glomerular hypertrophy and an increase in renocortical volume. Adaptive hyperfiltration by the remaining kidney is maintained at a constant level for at least 6-8 years after donation [33]. Renal hyperfiltration is associated with an increased risk of developing hypertension and CVD, and there is an association between renal hyperfiltration and decline in eGFR [34]. This may in part explain the increased risk of cardiovascular morbidity and mortality among living donors.

In a recent study by Yoon et al. [35], NGAL levels 1 week after donor nephrectomy, but not preoperative NGAL levels, were associated with an eGFR $<60 \mathrm{ml} / \mathrm{min} / 1.73 \mathrm{~m}^{2} 6$ months postoperatively. This supports our hypothesis that increased NGAL levels in kidney donors may be a biomarker for an increased risk of development of CKD.

FGF23 is a phosphaturic hormone with an important role in calcium-phosphate metabolism. FGF23 increases phosphate excretion, and FGF23 levels rise quickly as kidney function declines [13].

Increased levels of FGF23 are associated with increased mortality in hemodialysis patients [36], as well as in patients with CKD stages 2-4 [37] and kidney transplant patients [38]. Increased FGF23 levels combined with a reduced GFR predicts rapid progression toward ESRD $[39,40]$. Observational studies reported independent associations of elevated serum phosphate and FGF23 levels with risk of ESRD, CVD, and death. Excessive phosphate induces arterial calcification, and increased FGF23 probably reflects the phosphate load of the body [41]. Donor Nephrectomy Outcomes Research (DONOR) Network investigators found increased FGF23 levels 6 months after donation in an unselected group of donors [42]. In our study, the FGF23 levels were nonsignificantly increased in donors compared to controls, probably reflecting the subgroup of donors with well-preserved kidney function or a power problem.

There was no significant difference in levels of sKlotho between donors and controls, probably reflecting a near-normal eGFR in the donors. There was, however, a significant decrease in serum sKlotho in patients with CKD stages 4 and 5 compared to donors. Ever since its discovery about 15 years ago, sKlotho has been linked to reduced kidney function. sKlotho was originally identified as an antiaging protein, but at a later stage it has been shown to possess a number of biological functions [14]. sKlotho is expressed in different organs, but mostly in kidney tissue, especially in the distal tubular cells [43]. sKlotho was reported to be 
Thorsen et al.: Neutrophil Gelatinase-Associated Lipocalin, Fibroblast Growth

Factor 23, and Soluble Klotho in Long-Term Kidney Donors

closely associated with CKD progression [44-46], but another study found stable sKlotho levels in patients with CKD stages 2-4 [47]. Our results support the work of Pavik et al. [45], with a significant decrease in sKlotho in CKD stages 4 and 5, but it is still unclear if the serum levels of sKlotho reflect tissue Klotho.

\section{Strengths and Limitations}

The commercially available methods for the measurement of sKlotho differ in quality; thus, results may be difficult to compare between studies. The IBL kit used in this study showed a within-run variation of $4 \%$, with good agreement between serum and EDTA plasma in a study of the 3 different Klotho assays available [48].

Restriction and matching are the main methods of preventing confounding in an observational cohort study. Restriction is used in this study by having selected kidney donors with an eGFR $\geq 60 \mathrm{ml} / \mathrm{min} / 1.73 \mathrm{~m}^{2}$ to reduce confounding by reduced kidney function. We did not perform any matching. To further examine the results, we compared the 15 controls with the lowest eGFR (mean 87 and range $73-96 \mathrm{ml} / \mathrm{min} / 1.73 \mathrm{~m}^{2}$ ) to the 15 donors with the best eGFR (mean 88 and range 81-103 $\mathrm{ml} / \mathrm{min} / 1.73 \mathrm{~m}^{2}$ ). The NGAL level was nonsignificantly higher in donors than in controls ( 86 vs. $105 \mathrm{ng} / \mathrm{ml}$ ), showing a trend toward higher NGAL levels in a small sample. This finding supports - but does not confirm - that the increased level of NGAL in kidney donors is associated with the donation, and is not only the result of reduced postoperative kidney function. If, however, the increase in NGAL in this population of donors is the result of reduced kidney function, NGAL levels may still be important as a biomarker for people at risk of increased morbidity and mortality after donation.

The small number of patients included in this study is a limitation, and prospective studies are needed to evaluate these biomarkers as prognostic markers in kidney donors.

\section{Conclusion}

Long-term kidney donors have significantly higher levels of NGAL than healthy controls. This may reflect a partial loss of renal function in kidney donors as compared with a healthy control group. Renal hyperfiltration as a consequence of nephrectomy may induce cellular stress. NGAL is a potential biomarker for predicting donors at increased risk of developing CKD and premature mortality postoperatively. FGF23 levels have an inverse relationship to eGFR, and the level of sKlotho declines when eGFR declines; however, there is no significant difference in sKlotho and FGF23 levels between long-term kidney donors and controls. The hypothesis using NGAL as a prognostic marker for kidney donors should be tested prospectively in a larger cohort.

\section{Acknowledgments}

The authors would like to thank Geir Egil Eide, Biostatistician, PhD, Centre for Clinical Research, Haukeland University Hospital, Bergen, Norway, for statistical advice. The study was supported by an educational grant from Stavanger University Hospital and a grant from the Norwegian Society of Nephrology. 


\begin{tabular}{l|l}
\hline DOI: $10.1159 / 000450621$ & $\begin{array}{l}\text { (c) 2016 The Author(s). Published by S. Karger AG, Basel } \\
\text { www.karger.com/nne }\end{array}$ \\
\hline
\end{tabular}

Thorsen et al.: Neutrophil Gelatinase-Associated Lipocalin, Fibroblast Growth

Factor 23, and Soluble Klotho in Long-Term Kidney Donors

\section{Authors' Contributions}

- I.S. Thorsen: study design, recruiting patients, data collection, data analysis, and preparing the manuscript

- I.H. Bleskestad: data analysis and revision of the manuscript

- G. Jonsson: collecting and analyzing laboratory samples and revision of the manuscript

- $\quad$ Ø. Skadberg: analyzing laboratory samples and revision of the manuscript

- L.G. Gøransson: study design, data collection, data analysis, and preparing the manuscript

- All authors read and approved the final manuscript

\section{Disclosure Statement}

The authors declare no conflicts of interests.

\section{References}

$>1$ Hallan S, Astor B, Lydersen S: Estimating glomerular filtration rate in the general population: the second Health Survey of Nord-Trøndelag (HUNT II). Nephrol Dial Transplant 2006;21:1525-1533.

2 Levin A, Stevens PE: Summary of KDIGO 2012 CKD Guideline: behind the scenes, need for guidance, and a framework for moving forward. Kidney Int 2014;85:49-61.

-3 Viau A, El Karoui K, Laouari D, et al: Lipocalin 2 is essential for chronic kidney disease progression in mice and humans. J Clin Invest 2010;120:4065-4076.

-4 Hallan SI, Ritz E, Lydersen S, Romundstad S, Kvenild K, Orth SR: Combining GFR and albuminuria to classify CKD improves prediction of ESRD. J Am Soc Nephrol 2009;20:1069-1077.

5 Leivestad T: Annual report 2014. The Norwegian Renal Registry. http://www.nephro.no/nnr/AARSM2014.pdf.

-6 Segev DL, Muzzale AD, Caffo BS, Mehta SA, Singer AL, Taranto SE, McBride MA, Montgomery RA: Perioperative mortality and long-term survival following live kidney donation. JAMA 2010;303:959-966.

-7 Lam NN, Lentine KL, Levey AS, Kasiske BL, Garg AX: Long-term medical risks to the living kidney donor. Nat Rev Nephrol 2015;11:411-419.

-8 Flanigan WJ, Burns RO, Takacs FJ, Merrill JP: Serial studies of glomerular filtration rate and renal plasma flow in kidney transplant donors, identical twins, and allograft recipients. Am J Surg 1968;116:788-794.

-9 Gaston RS, Kumar V, Matas AJ: Reassessing medical risk in living kidney donors. J Am Soc Nephrol 2015;26: 1017-1019.

10 Mjøen G, Hallan S, Hartmann A, Foss A, Midtvedt K, Øyen O, Reisæter A, Pfeffer P, Jenssen T, Leivestad T, Line PD, Øvrehus M, Dale DO, Pihlstrøm H, Holme I, Dekker FW, Holdaas H: Long-term risks for kidney donors. Kidney Int 2014;86:162-167.

11 Liu Q, Ryon J, Nilsen-Hamilton M: Uterocalin: a mouse acute phase protein expressed in the uterus around birth. Mol Reprod Dev 1997;46:507-514.

-12 Mitsnefes MM, Kathman TS, Mishra J, Kartal J, Khoury PR, Nickolas TL, Barasch J, Devarajan P: Serum neutrophil gelatinase-associated lipocalin as a marker of renal function in children with chronic kidney disease. Pediatr Nephrol 2007;22:101-108.

13 Gutierrez O, Isakova T, Rhee E, et al: Fibroblast growth factor-23 mitigates hyperphosphatemia but accentuates calcitriol deficiency in chronic kidney disease. J Am Soc Nephrol 2005;16:2205-2215.

14 Kuoro-o M: Klotho and aging. Biochim Biophys Acta 2009;1790:1049-1058.

15 Levey AS, Stevens LA, Schmid CH, Zhang Y, Castro AF 3rd, Feldman HI, Kusek JW, Eggers P, Van Lente F, Greene T, Coresh J: A new equation to estimate glomerular filtration rate. Ann Intern Med 2009;150:604-612.

-16 Yamazaki Y, Okazaki R, Shibata M, et al: Increased circulatory level of biologically active full-length FGF-23 in patients with hypophosphatemic rickets/osteomalacia. J Clin Endocrinol Metab 2002;87:4957-4960.

17 Yamashita H, Yamashita T, Miyamoto M, et al: Fibroblast growth factor (FGF)-23 in patients with primary hyperparathyroidism. Eur J Endocrinol 2004;151:55-60.

-18 Yamazaki Y, Imura A, Urakawa I, et al: Establishment of sandwich ELISA for soluble $\alpha$-Klotho measurement: age-dependent change of soluble $\alpha$-Klotho levels in healthy subjects. Biochem Biophys Res Commun 2010; 398:513-518.

19 Pedersen L, Pedersen SM, Brasen CL, Rasmussen LM: Soluble serum Klotho levels in healthy subjects. Comparison of two different immunoassays. Clin Biochem 2013;46:1079-1083.

20 Naesgaard PA, León De La Fuente RA, Nilsen ST, Woie L, Aarsland T, Brede C, Staines H, Nilsen DW: Serum 25(OH)D is a 2-year predictor of all-cause mortality, cardiac death and sudden cardiac death in chest pain patients from Northern Argentina. PLoS One 2012;7:e43228. 


\begin{tabular}{l}
\hline Nephron Extra 2016;6:31-39 \\
\hline DOI: 10.1159/000450621 \\
\hline
\end{tabular}

Thorsen et al.: Neutrophil Gelatinase-Associated Lipocalin, Fibroblast Growth

Factor 23, and Soluble Klotho in Long-Term Kidney Donors

21 Holick MF, Binkley NC, Bischoff-Ferrari HA, Gordon CM, Hanley DA, Heaney RP, Murad MH, Weaver CM: Evaluation, treatment, and prevention of vitamin D deficiency: an Endocrine Society clinical practice guideline. J Clin Endocrinol Metab 2011;96:1911-1930.

-22 Pedersen KR, Ravn HB, Hjortdal VE, Nørregaard R, Povlsen JV: Neutrophil gelatinase-associated lipocalin (NGAL): validation of commercially available ELISA. Scand J Clin Lab Invest 2010;70:374-382.

-23 Burnett SM, Gunawardene SC, Bringhurst FR, Jüppner H, Lee H, Finkelstein JS: Regulation of C-terminal and intact FGF-23 by dietary phosphate in men and women. J Bone Miner Res 2006;21:1187-1196.

24 Allen RA, Erickson RW, Jesaitis AJ: Identification of a human neutrophil protein of $M_{\mathrm{r}} 24000$ that binds $N$-formyl peptides: co-sedimentation with specific granules. Biochim Biophys Acta 1989;991:123-133.

25 Bolignano D, Donato V, Coppolino G, Campo S, Buemi A, Lacquaniti A, Buemi M: Neutrophil gelatinase-associated lipocalin (NGAL) as a marker of kidney damage. Am J Kidney Dis 2008;52:595-605.

-26 Malyszko J, Malyszko JS, Bachorzewska-Gajewska, Poniatowski B, Dobrzycki S, Mysliwiec M: Neutrophil gelatinase-associated lipocalin is a new and sensitive marker of kidney function in chronic kidney disease patients and renal allograft recipients. Transplant Proc 2009;41:158-161.

-27 Salanzadeh J, Sahraee Z, Nafar M, Parwin M: Delayed graft function (DGF) after living donor kidney transplantation: a study of possible explanatory factors. Ann Transplant 2012;17:69-76.

28 Parikh CR, Jani A, Mishra J, Ma Q, Kelly C, Barasch J, Edelstein CL, Devarajan P: Urine NGAL and IL-18 are predictive biomarkers for delayed graft function following kidney transplantation. Am J Transplant 2006;6: 1639-1645.

29 Izquierdo MJ, Cavia M, Muñiz P, de Francisco AL, Arias M, Santos J, Abaigar P: Paricalcitol reduces oxidative stress and inflammation in hemodialysis patients. BMC Nephrol 2012;13:159.

-30 Smith ER, Lee D, Cai MM, Tomlinson LA, Ford ML, McMahon LP, Holt SG: Urinary neutrophil gelatinase-associated lipocalin may aid prediction of renal decline in patients with non-proteinuric Stages 3 and 4 chronic kidney disease (CKD). Nephrol Dial Transplant 2013;28:1569-1579.

-31 Bolignano D, Lacquaniti A, Coppolino G, Donato V, Campo S, Fazio MR, Nicicia G, Buemi M: Neutrophil gelatinaseassociated lipocalin (NGAL) and progression of chronic kidney disease. Clin J Am Soc Nephrol 2009;4:337-344.

-32 Mori K, Nakao K: Neutrophil gelatinase-associated lipocalin as the real-time indicator of active kidney damage. Kidney Int 2007;71:967-970.

-33 Lenihan CR, Busque S, Derby G, Blouch K, Myers BD, Tan JC: Longitudinal study of living kidney donor glomerular dynamics after nephrectomy. J Clin Invest 2015;125:1311-1318.

-34 Park M, Yoon E, Lim YH, Kim H, Choi J, Yoon HJ: Renal hyperfiltration as a novel marker of all-cause mortality. J Am Soc Nephrol 2015;26:1426-1433.

-35 Yoon YE, Chi YI, Kin SY, Lee HH, Huh KH, Kim YS, Han WK: Plasma neutrophil gelatinase-associated lipoprotein in living kidney donors. Transplant Proc 2016;48:738-741.

-36 Gutiérrez OM, Mannstadt M, Isakova T, Rauh-Hain JA, Tamez H, Shah A, Smith K, Lee H, Thadhani R, Jüppner H, Wolf M: Fibroblast growth factor 23 and mortality among patients undergoing hemodialysis. N Engl J Med 2008;359:584-592.

37 Wolf M: Update on fibroblast growth factor 23 in chronic kidney disease. Kidney Int 2012;82:737-747.

-38 Wolf M, Molnar MZ, Amaral AP, Czira ME, Rudas A, Ujszaszi A, Kiss I, Rosivall L, Kosa J, Lakatos P, Kovesdy CP, Musci I: Elevated fibroblast growth factor 23 is a risk factor for kidney transplant loss and mortality. J Am Soc Nephrol 2011;22:956-966.

-39 Isakova T, Xie H, Yang W, Xie D, Anderson AH, Scialla J, Wahl P, et al: Fibroblast growth factor 23 and risks of mortality and end-stage renal disease in patients with chronic kidney disease. JAMA 2011;305:2432-2439

-40 Kendrick J, Cheung AK, Kaufman JS, Greene T, Roberts WL, Smits G, Chondrol M: FGF-23 associates with death, cardiovascular events, and initiation of chronic dialysis. J Am Soc Nephrol 2011;22:1913-1922.

-41 Isakova T, Ix JH, Sprague SM, Raphael KL, Fried L, Gassman JJ, Raj D, Cheung AK, Kusek JW, Flessner MF, Wolf M, Block GA: Rationale and approaches to phosphate and fibroblast growth factor 23 reduction in CKD. J Am Soc Nephrol 2015;26:2328-2339.

-42 Young A, Hodsman AB, Boudville N, Geddes C, Gill J, Goltzman D, Jassal SV, Klarenbach S, et al: Bone and mineral metabolism and fibroblast growth factor 23 levels after kidney donation. Am J Kidney Dis 2012;59:761-769.

43 Hu MC, Kuro-o M, Moe OW: The emerging role of Klotho in clinical nephrology. Nephrol Dial Transplant 2012; 27:2650-2657.

-44 Kim HR, Nam BY, Kim DW, Kang HW, Han JH, Lee MJ, Shin DH, Doh FM, Koo HM, et al: Circulating $\alpha$-klotho levels in CKD and relationship to progression. Am J Kidney Dis 2013;61:899-909.

45 Pavik I, Jaeger P, Ebner L, Wagner CA, Petzold K, Spichtig D, Poster D, Wüthrich RP, Russmann S, Serra AL: Secreted Klotho and FGF23 in chronic kidney disease Stage 1 to 5: a sequence suggested from a cross-sectional study. Nephrol Dial Transplant 2013;28:352-359.

-46 Shinamura Y, Hamada K, Inoue K, Ogata K, Ishihara M, Kagawa T, Inoue M, et al: Serum levels of soluble secreted $\alpha$-Klotho are decreased in the early stages of chronic kidney disease, making it a probable novel biomarker for early diagnosis. Clin Exp Nephrol 2012;16:722-729.

-47 Seiler S, Wen M, Roth HJ, Fehrenz M, Flügge F, Herath E, Weihrauch A, Fliser D, Heine GH: Plasma Klotho is not related to kidney function and does not predict adverse outcome in patients with chronic kidney disease. Kidney Int 2013;83:121-128.

-48 Heijboer AC, Blankenstein MA, Hoenderop J, de Borst MH, Vervloet MG; NIGRAM Consortium: Laboratory aspects of circulating $\alpha$-Klotho. Nephrol Dial Trasplant 2013;28:2283-2287. 